\title{
A delicate balance
}

Should we return green crop residues to the soil? Returning crop residues to soil
for decomposition is considered a common management practice, but it can result
in increased emissions of in increased emissions of nitrous oxide $\left(\mathrm{N}_{2} \mathrm{O}\right)$, a potent greenhouse gas. Dr Gwenaëlle from INRAE, the French National Research Institute for Agriculture, Food and collaboration with European partners the decomposition of nine crop residues, correlating chemical composition of the residues to help understa agricultural practice.

ver the past few decades, we
have come to understand a
la lot more about the climate crisis and environmental protection, and our impact on them. Research on the warming effect of the greenhouse gas (GHG) emissions of everyday activities such as agriculure, animal husbandry, and fossi-fuelled transport, is constantly perspective We now have a come of research available on best practices, emerging issues, potential solutions, and Lashermes, Dr Sylvie Recous, Environment, investigated in $\mathrm{N}_{2} \mathrm{O}$ emissions with the

become bad practice as new evidence and understanding comes to light.

THE ISSUE WITH CROP RESIDUES The cycle of crop production is one area that researchers are beginning to realise is perhaps more complex than we once believed. The process includ soil preparation, seeding, fertilising Each step is very important and directly related to the production of crops of a certain quality and quantity for various

Proper handling of this biomass is very important and to date mainly involves burning or recycling back to the soil.
blue-sky developments. Dealing with GHG emissions might sound simple - 'do or don't do this and the situation will eventually improve' - but, in reality, it is much more complicated. Solutions need education and behaviour change on a global level, but also have to account cycle of life 'Best practice' can quickly
purposes. An important post-harvest step, which can also be considered as part of soil preparation, is the handling of crop residues, a process that has been shown to be of paramount importance in the cycle of crop production. Crop residues - the leftovers' from harvesting of props that have no obviousty bed parts use, for example the leaves and hairs from a cob of corn, or straw from a whe crop. Depending on the crop in question, leaves, stalks, and seed pods can all be crop residues. It doesn't take much to realise that these residues add up to a huge mass, equal to if not larger than the mass of the collected crops themselves.
Proper handling of this biomass is very important and to date mainly involves burning or recycling back to the soil. Returning crop residues to the soil to decompose is considered advantageous, as the decomposition process can act as an enrichment step for the soil, preparing the soil's orgunic of plan ing. It maintains soil life, and is essential for maintaining

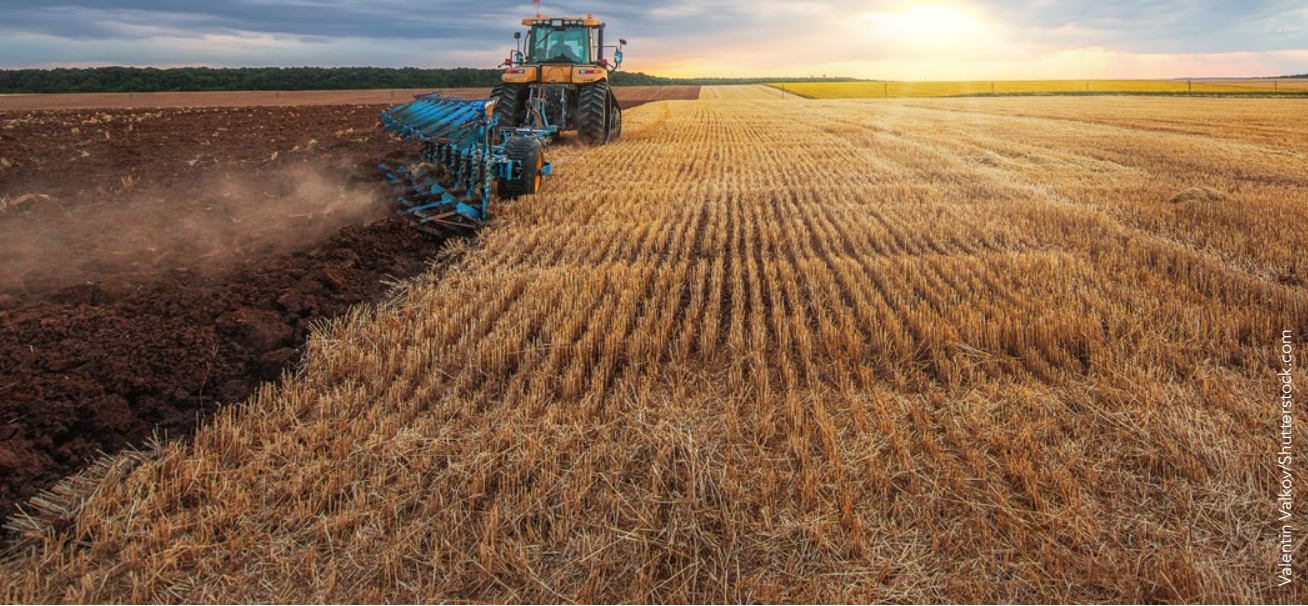

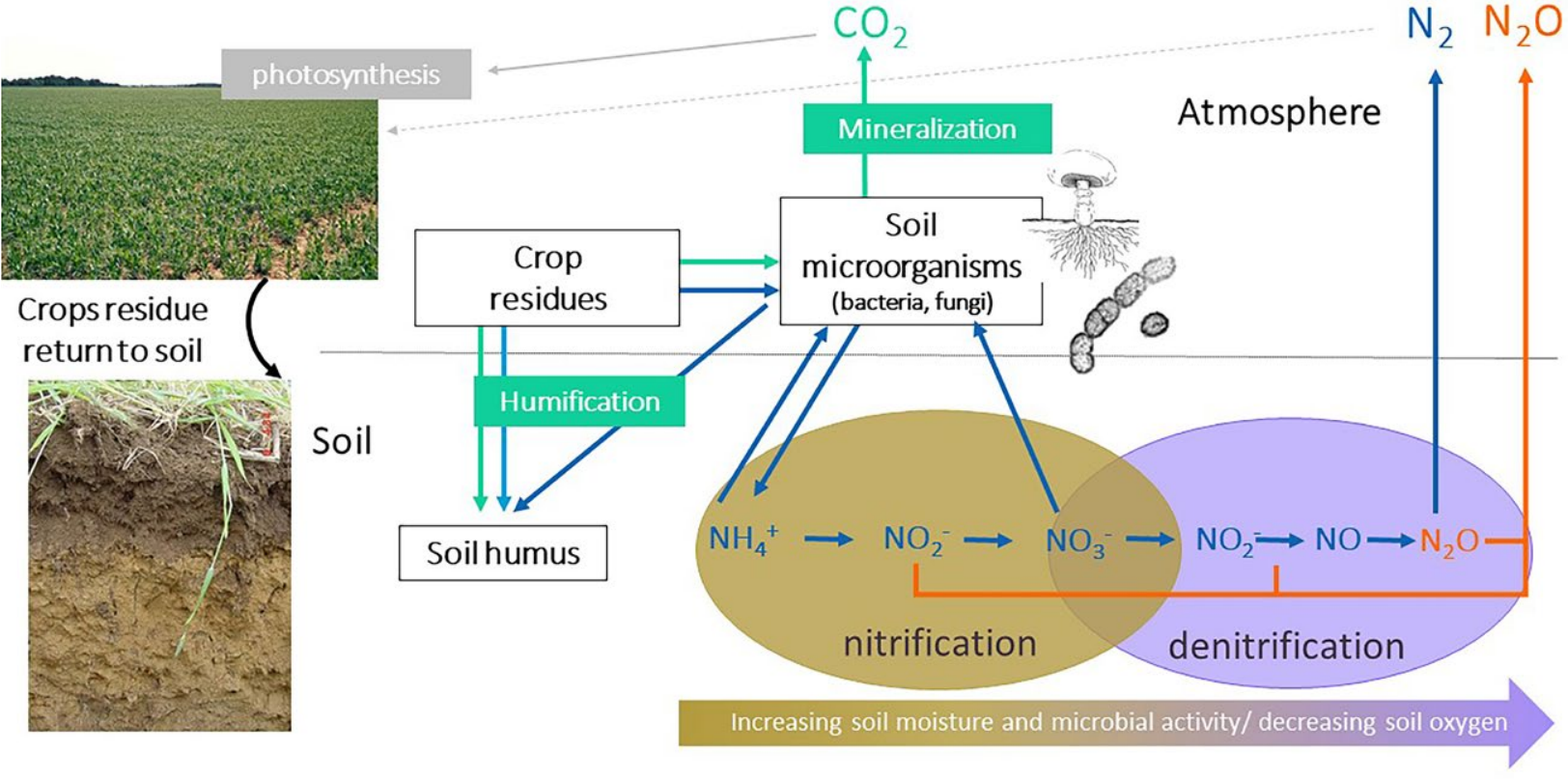

Returning crop residues to soil for decor

soil structure and fertility. Furthermore, crop residue decomposition can improve than $75 \%$ of $\mathrm{N}_{2} \mathrm{O}$ emissions are attributed the capture of $\mathrm{CO}_{2}$ emissions in the to human activities related to agriculture: atmosphere). There has been a lot of research into the mechanisms of this carbon sequestration process. A 2017 review paper on the subject revealed interaction between storage mechanisms and the ecosystem and questions whether the carbon the whole story.

\section{AGRICULTURE AND}

ITROGEN PRODUCTION (hvestigating the sustainablity of this crop-management pracice is the focus of a new paper by Dr Gwonalle Gonzague Alavoine of INRAE, the French National Research Institute fo Agriculture, Food and Environment. With expertise in environmental science, agronomy, soil science, the microbial ecology of soils, and physica measurements, these researchers have focused on the aftermath of crop residue decomposition. Their recent work targets the production of nitrous oxide $\left(\mathrm{N}_{2} \mathrm{O}\right)$ during decomposition. $\mathrm{N}_{2} \mathrm{O}$ is a GHG not as 'well-known' as $\mathrm{CO}_{2}$ or methane $\left(\mathrm{CH}_{4}\right)$ but much more impacttul than both, with an effect on global warming 265 and 25 times higher than $\mathrm{CO}_{2}$ and $\mathrm{CH}_{4}$ respectively, and a longer lifetime than them boht. Allough $\mathrm{N}_{2} \mathrm{O}$ concentration of crops.

Crop residues decompose in various stages and release mineral nitrogen

nitrification and denitrification being two important processes. During nitrification, nitrogen-bearing chemicals, with nitrate being the form most easily absorbed by plants. During denitrification, nitrate is converted to $\mathrm{N}_{2} \mathrm{O}$ from microorganisms under specific conditions. Denitrification can be considered as loss of nitrogen
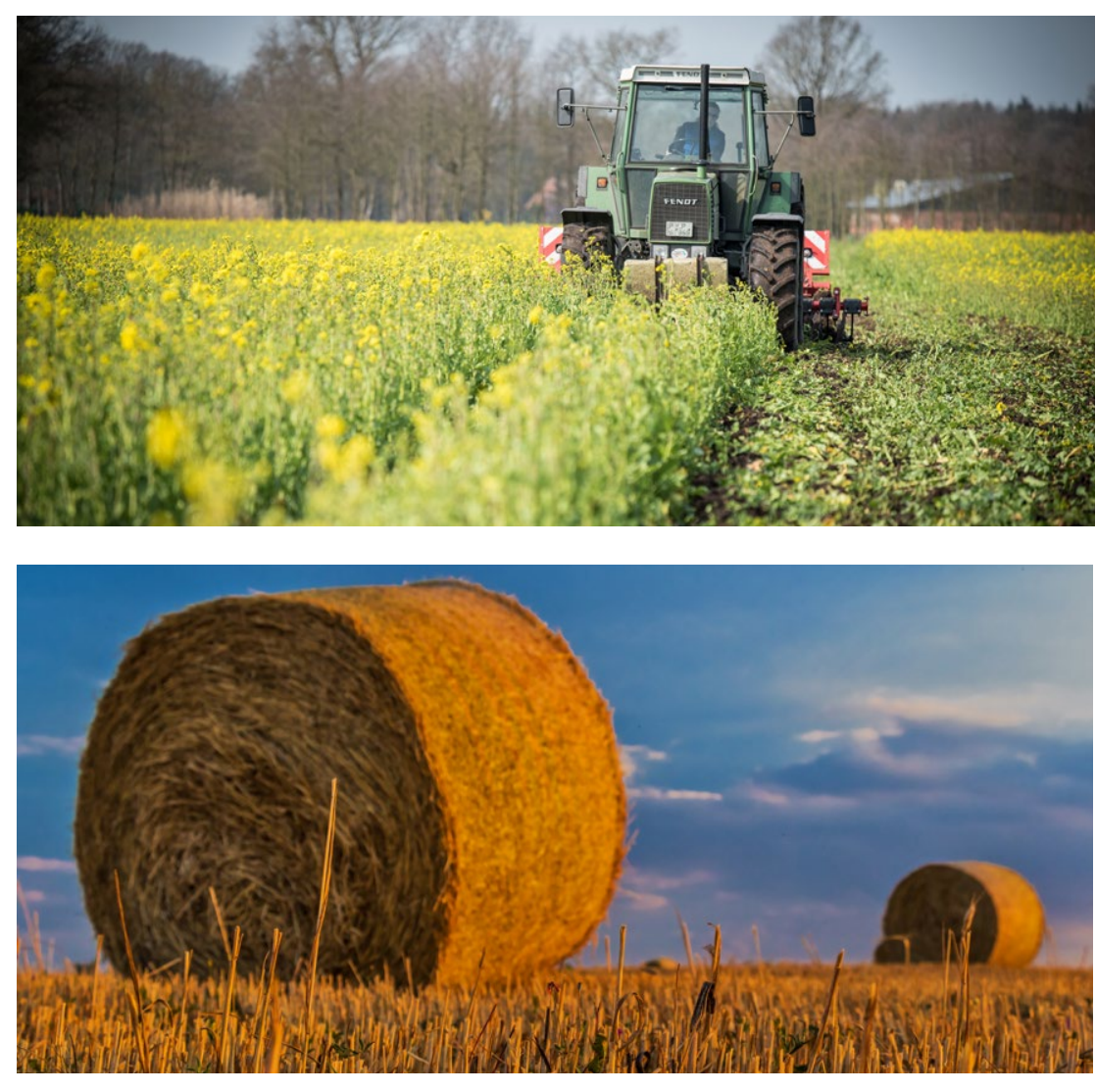


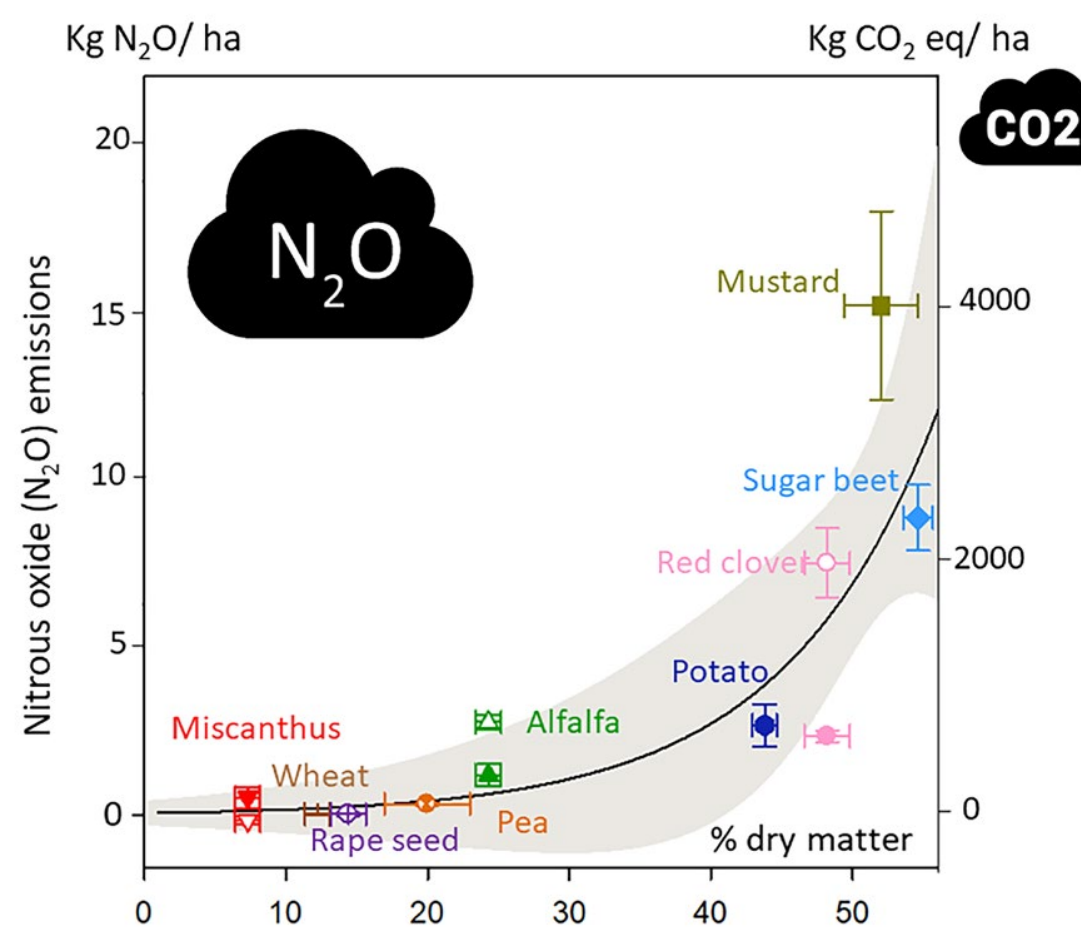

Content in soluble compounds of the crop residue

Decomposition of crop residues from nine different sources. Miscanthus had the lowest $\mathrm{N}_{2} \mathrm{O}$ emissions.

The new study revealed that the fraction of components soluble in neutral detergent present in crop residues (SOL-NDS) had the highest impact on

\section{$\mathrm{N}_{2} \mathrm{O}$ production.}

from soil to the environment in the form of $\mathrm{N}_{2} \mathrm{O}$ and, as the researchers show, it can and the conditions of the soil.

\section{$\mathrm{N}_{2} \mathrm{O}$ EMISSIONS VARY BY}

\section{CROP RESIDUE}

Lashermes, Recous and Alavoine examined the decomposition of crop residues from nine different sources (sugar beet, wheat, rape seed, potato, pea, mustard, red clover, alfalfa, and miscanthus) in two soll environments. The experimental set-up consisted of a compressed pellet of soil mixed with crop residues at the same ratio of mass creside per mass of soll, which was monitored over 60 days, recording the (production of $\mathrm{CO}_{2}$ from (production $\mathrm{C}_{2} \mathrm{CO}_{2}$ from carbonaceous characterised the crop residues with regards to porosity, chemical composition (percentage of $\mathrm{C}$ and $\mathrm{N}$, solubility in wat and in neutral detergent), and maturity researchers sought to identy und the correlations across these factors and the production of $\mathrm{N}_{2} \mathrm{O}$.

Their results confirmed the pre-existing knowledge that crop residues with a C:N ratio lower than 30 (accepted threshold) produced more $\mathrm{N}_{2} \mathrm{O}$ that residues with a ratio over 30 . Importantly, however, they also showed that the C:N ratio was not the main predictor for $\mathrm{N}_{2} \mathrm{O}$ production during decomposition. The new study revealed in neutral detergent present in crop residues (SOL-NDS) had the highest that the fraction of components soluble shown to produce higher emissions of the nine crop residues, the with the lowest $\mathrm{N}_{2} \mathrm{O}$ emissions was miscanthus, and the highest emissions were shown for sugar beet and mustard residues. These latter are crops that are returned to the soil when they are physiologically immature or (in the case of beets) just mature. In practice this means that crop residues which are still immature or 'green' when returned to soil for decomposition will tend to produce more $\mathrm{N}_{2} \mathrm{O}$ emissions. As the plant matures and its cell walls become richer in cellulose and lignin, the soluble matter disappears. Other factors, such as initial moisture levels, nitrogen content, and water-soluble $C$ and $N$ contents of the residues, were found to to be less explan

Importantly the researchers show that, under certain conditions, the $\mathrm{N}_{2} \mathrm{O}$ emissions from these decomposing residues can even completely cancel out any benefits gained from the contribution to carbon sequestration in the soil. They suggest that emissions from these younger crop residues are likely currently

\section{CROP RESIDUE DECOMPOSITION}

EFFECTS ON GHG EMISSIONS

Through this study, Lashermes, Recous and Alavoine have shown for the first tim that $\mathrm{N}_{2} \mathrm{O}$ emissions can be explained by def .

Despite correlating $\mathrm{N}_{2} \mathrm{O}$ emissions with the chemical composition and maturity of crop residues, the researchers emphasise that the overall contribution of $\mathrm{N}_{2} \mathrm{O}$ produced from crop residue decomposition is still not clear. More research is needed to quantify the effect of emitted $\mathrm{N}_{2} \mathrm{O}$ on the total GHG emissions, but also to assess whether the possible damage resulting from these emissions is mitigated by the potential benefits of crop decomposition, including supporting biodiversity, protection from soil erosion, and fertilisation of soll for its next use. It's a complex issue, and before rushing into conclusions.

\section{Behind the Research}

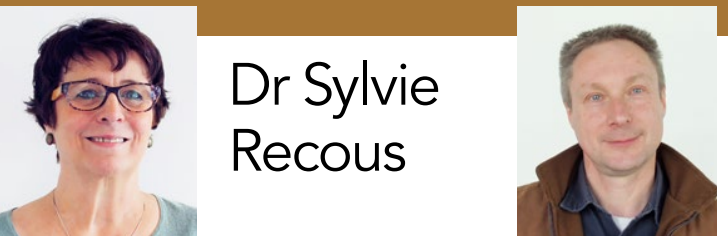

Engr Gonzague

Alavoine

E: gwenaelle.lashermes@inrae.fr T: $+33(0) 326773582$ W: INRAE staff profile G Lashermes @GLashermes @SRecous @ @FARE Reims

Research Objectives

Understanding the impact on greenhouse gas emissions of returning crop residues to the soil.

\section{Detail}

\section{Address}

Fractionation of AgroResources and ENwion Reims, France

Bio

Gwenaëlle Lashermes is a research scientist at INRAE, the French National Research Institute for Agriculture, Food and Environment. She is lab deputy director of the FARE laboratory. She has a PhD in environmental science (AgroParisTech University) and an engineering and MSc degrees in (AgroCampus Mest Universityl.

\section{References}

Lashermes, G, Recous, S, Alavoine, G, et al, (2022) $\mathrm{N}_{2} \mathrm{O}$ emissions from decomposing crop residues are strongly linked to their initial soluble fraction and early $C$ mineralization. Sci Total Environ, 806, 150883. 10.1016/j.scitotenv.2021.150883

Dignac, MF, Derrien, D, Barre, P, et al, (2017) Increasing soil carbon storage: mechanisms, effects of agricultural practices and proxies. A review. Agron Sustain Dev, $37(14)$. 10.1007/s13593-017-0421-2

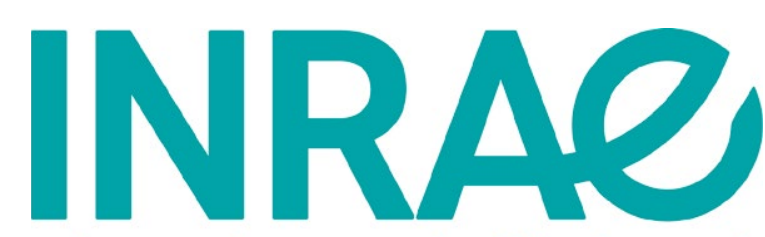

science for people, life \& earth
Funding

ACCE ERA-GAS:

ResidueGas project. European Union's Program grant agreement No 696356 the French funding grant number ANR17-EGAS-0003. - The AgroEcoSystem division of INRAE (France)

\section{Collaborators}

- Baldur Janz

- Klaus Butterbach-Bah

- Maria Ernfors

- Patricia Laville

Olesen
A denne). He is leader of the FAR

microbiology, enzymology and

biogeochemistry activities.

\section{Personal Response}

\section{Could a pre-treatment of crop residues, or addition of} Comission of $\mathrm{N}_{2} \mathrm{O}$ ?

II A pre-treatment of residues is difficult, or even unrealistic at field- and farm scale, as it would require additional environmental and economic costs (extra chemical or . reduce $\mathrm{N}_{2} \mathrm{O}$ emissions Practices thair promote biological ctivity a solo of residues to the soil when it is waterlogged after heavy ains or compacted by the passage of farm machinery. The synchronisation of the release of nitrogen during decomposition with the needs of the next crop by choosing the plant species and the date of destruction of the cover
crop is important. The use of chemical nitrification inhibitors or timporition reduce emissions. 